\title{
Comparison of different deconvolution algorithms for voxel-wise quantitative MR perfusion assessment
}

\author{
Niloufar Zarinabad Nooralipour ${ }^{1 *}$, Amedeo Chiribiri ${ }^{2}$, Gilion Hautvast ${ }^{3}$, Andreas Schuster $^{1}$, Philip Batchelor $^{1}$, \\ Sven Plein ${ }^{4}$, Eike Nagel ${ }^{5}$
}

From 2011 SCMR/Euro CMR Joint Scientific Sessions

Nice, France. 3-6 February 2011

\section{Objective}

To apply deconvolution algorithms to voxel-wise analysis of first-pass myocardial perfusion MR data and to determine how noise affects perfusion estimation using different quantification methods.

\section{Background}

One of the main advantages of cardiac first-pass perfusion MR is its high spatial resolution. Though several methods have been used to quantify myocardial perfusion rate, no previous work has been done on voxelwise analysis and published methods were applied to standard myocardial segments. Signal-to-noise ratio (SNR) might negatively affect the accuracy of the measurements obtained with methods developed for segmental analysis.

\section{Methods}

Fermi function modelling, auto-regressive movingaverage model (ARMA), model-independent approach using B-spline-basis and exponential-basis deconvolution were used to quantify myocardial perfusion rate in 6 patients. Perfusion data were acquired on a 3 Tesla Philips CMR scanner in three LV short axis slices with a saturation recovery gradient echo method (TR/TE $3.0 \mathrm{~ms} / 1.0 \mathrm{~ms}$, flip-angle $15^{\circ}$; effective kt-SENSE acceleration 3.8 , spatial resolution $1.2 \times 1.2 \times 10 \mathrm{~mm})$ during adenosine-induced hyperaemia $(140 \mu \mathrm{g} / \mathrm{kg} / \mathrm{min})$ using $0.05 \mathrm{mmol} / \mathrm{kg}$ Gd-DTPA (Magnevist, Schering, Germany) at $4 \mathrm{ml} / \mathrm{minute}$ followed by a $20 \mathrm{ml}$ saline flush. Voxelwise perfusion estimates were compared to the results

'Division of imaging Sciences, King's College London, London, UK Full list of author information is available at the end of the article obtained from segmental analysis, for different levels of spatial averaging (10 voxels - 1 segment - whole slice). The data shown in Figure 1 represent the curve fit relative error, the square root of the sum of squared difference between the measured tissue data and the estimated tissue data, computed by convolving the measured blood data with the estimated tissue kernel, divided by the norm of measured tissue data.

\section{Results}

ARMA method analysis resulted in the lowest model curve-fit error for different level of noise in both rest and stress condition. Exponential deconvolution had a lower error when compared to Fermi function modelling and model independent analysis (Figure 1A). The overall rest and stress error was in the voxel-wise/segment-wise analyses $0.6 \% / 0.5 \%$ for ARMA, $3.2 / 2.4 \%$ for exponential, $4 \% / 3.3 \%$ for Fermi, and $7 \% / 5.6 \%$ for B-spline deconvolution, respectively.

The curve-fit error increased when analyzing rest perfusion images, most likely as a result of the increased baseline signal intensity values or of a lower perfusion rate in the rest images, acquired after stress.

\section{Conclusion}

This study confirms the importance of adequate SNR in first-pass perfusion images. Before voxel-wise analysis can be used in clinical practice, more studies will be needed to define the best algorithms to deal with reduced SNR typical for voxel-wise tissue data. ARMA approach and Exponential basis deconvolution were the least sensitive methods to noise. 


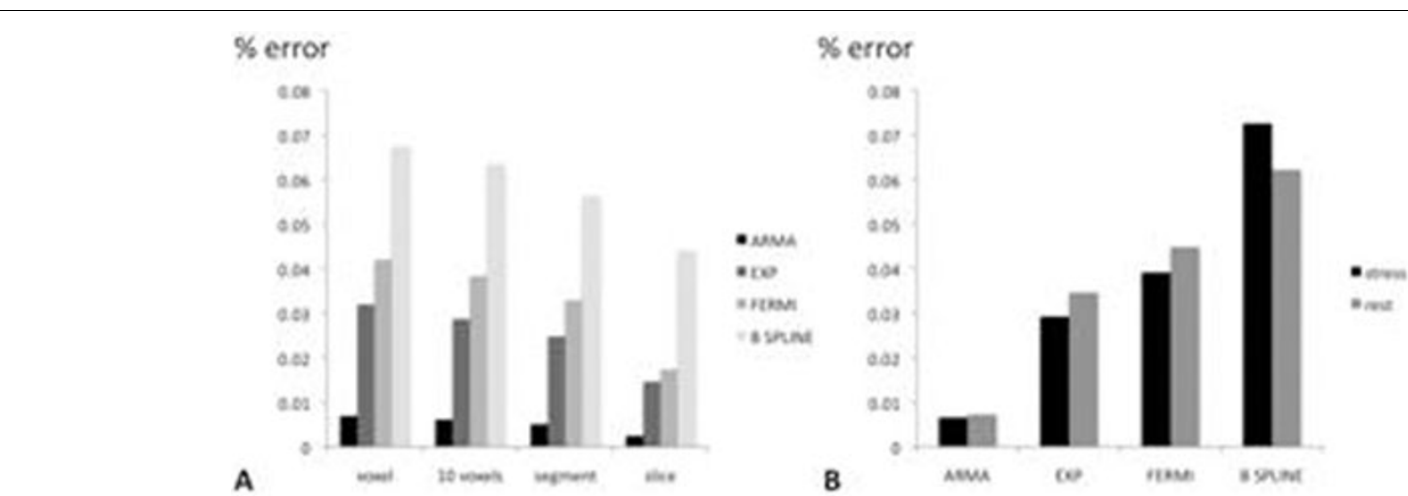

Figure 1 Comparison of relative curve fit error for different levels of SNR for ARMA, exponential, Fermi and B-spine deconvolution (A). Relative error was found to be higher for rest perfusion images (B).

\section{Author details}

'Division of imaging Sciences, King's College London, London, UK.

${ }^{2}$ Wellcome Trust - EPSRC Centre of Excellence in Medical Engineering, London, UK. ${ }^{3}$ Philips Healthcare, Imaging Systems - MR, Best, Netherlands.

${ }^{4}$ D7University of Leeds, Multidisciplinary Cardiovascular Research Centre and Division of Imaging Sciences, King's College London, Leeds-London, UK. ${ }^{5}$ Di1King's College London, Wellcome Trust - EPSRC Centre of Excellence in Medical Engineering, London, UK.

Published: 2 February 2011

doi:10.1186/1532-429X-13-S1-P59

Cite this article as: Nooralipour et al:: Comparison of different

deconvolution algorithms for voxel-wise quantitative MR perfusion

assessment. Journal of Cardiovascular Magnetic Resonance 2011 13(Suppl

1):P59.

Submit your next manuscript to BioMed Central and take full advantage of:

- Convenient online submission

- Thorough peer review

- No space constraints or color figure charges

- Immediate publication on acceptance

- Inclusion in PubMed, CAS, Scopus and Google Scholar

- Research which is freely available for redistribution

Submit your manuscript at www.biomedcentral.com/submit 